\title{
Study on Knowledge level of Dog Owners towards Rabies Prevention and Control
}

\author{
B. C. Das ${ }^{1 *}$, S. R. Khatua ${ }^{2}$, V. S. Shivani ${ }^{3}$, S. Samanta ${ }^{3}$ and N. Priyadarshini ${ }^{4}$ \\ ${ }^{1}$ Department of Veterinary and A.H Extension, ${ }^{2}$ Department of Microbiology, ${ }^{3}$ Department of \\ $A R G O$, College of Veterinary Science and Animal Husbandry, Odisha University of \\ agriculture and technology, Bhubaneswar, India \\ ${ }^{4}$ DAH\&VS, Government of Odisha, India \\ *Corresponding author
}

\section{A B S T R A C T}

\section{Keywords}

Knowledge,

Practice, Rabies, Vaccination, Dog owners

\section{Article Info}

\section{Accepted:}

20 December 2020

Available Online:

10 January 2021
Rabies is a viral and fatal disease of high zoonotic significance, with almost $100 \%$ case fatality rate. This disease occurs in more than 150 countries and territories and about 55000 people die of rabies every year, mostly in Africa, Asia, and South America. Worldwide, dogs are the source of $99 \%$ of human rabies deaths (WHO, 2010). Canine rabies is endemic and occurs throughout the year in all parts of India. A study was conducted to assess knowledge level, attitude and dog ownership patterns related to rabies prevention and control and to assess rabies vaccination coverage of dogs in Bhubaneswar city. Structured questionnaires were prepared and administered to 100 dog owners by face to face interview. The study revealed that majority of the dog owners were aware that rabies can be spread through the saliva of a rabid animal. However, majority of respondents did not know the age for first vaccination of dogs against rabies. Dog owners who were government servants were having good knowledge about rabies than those of other occupation groups. Positive attitude towards rabies increased with increase in age of dog owners. Female dog owners do have less knowledge as compared to their male counterparts. Inadequate knowledge of some aspects of rabies, negative attitude and practice of dog owners towards rabies put the dog owners in high risk of exposure to the fatal disease. There is, therefore a need for educational programmes targeted at dog owners to increase their level of knowledge and reduce the risk of exposure to rabies.

\section{Introduction}

The majority of the households in urban areas keep dogs as common pet animals. Dogs perform many activities for the society such as companionship, hunting, protection, assisting police in catching theft, defense etc. They are now considered as "man's best friends" (Kaud, 2016).Dog breeding is also becoming popular day by day and people keep dogs for their livelihood. Their livelihood is seriously being affected by many infectious and systemic diseases of dogs due to low level of awareness and scientific practice. Pyometra is mainly a disease of female dogs and a lot of scientific works have 
been done in various parts of the world and effective therapeutic protocols have been recommended by various workers to control and prevent its occurrence (Jena et al., 2013 and Sethi et al., 2020). However, rabies is a viral and fatal disease of high zoonotic significance, with almost $100 \%$ case fatality rate. The disease originated about 3000BC and is one of the most typical zoonoses that have been well known since ancient times. Every year, more than 15 million people worldwide receive a post-exposure preventive regimen to avert this disease, this is estimated to prevent 327000 rabies deaths annually (WHO, 2010). The disease is endemic in developing countries like India (Harry et al., 1984) and is often misdiagnosed, underdiagnosed and underreported. As per report of $19^{\text {th }}$ livestock census, Government of India, the dog population in India is around 25 million and the dog to man ratio is estimated to be 1:36. The annual estimated number of dog bites in India is 17.4 million which cause an estimated 18,000-20,000 human rabies cases per year. The dog population of Capital city of Odisha i.e. Bhubaneswar city is around 25, 000 and the Capital Hospital of the city where post bite human antirabies vaccine are given free of cost receives 30 to 40 dog bite cases every day. As per data of the Kennel Club of India which registered some 50,000 pet dogs last year, every year on an average the number of new pets increases by 15 per cent. Another $30-40$ per cent of the canine population is not registered with kennels.

The pet dog population in India is growing for a number of reasons. On top of the list is a love for dogs. Some of the factors responsible for the growing trend of pet dog ownership in urban India are nuclear families, double income households, and changing lifestyles. The one-child norm has also contributed towards increase in pet dog population. Other believes that holds increase in pet dog population is that of security. With a rise in prosperity, more and more people are keeping pet dogs for safety.

Dog owners' family members and their neighbors are placed in the high risk group for rabies because of their frequent exposure to dogs. The data on dog bites are scanty, unreliable and controversial since they are not notifiable in the routine surveillance system. Studies on knowledge, attitude and practice (KAP) towards rabies among dog owners have been carried out in different parts of the country and these have shown that KAP is an important factor in the control of rabies in India. Poor public awareness towards rabies is considered as one of the bottle necks for the prevention and control of the disease. In India, understanding dog owner's knowledge level on cause, mode of transmission, symptoms, treatment and possible intervention measures of rabies is an important step towards developing strategies aimed at controlling the disease and determining the level of implementation of planned activities in the future. Therefore, this study was designed to assess the level of knowledge of dog owners in Bhubaneswar city of Odisha towards prevention and control of rabies. The present study was carried out with three important objectives: (i) to studythe socio economic profile of the pet owners, (ii) to assess the level knowledge of dog owners towards control and prevention of rabies and (iii)to study the co-relation between selected independent variables and the knowledge level of the respondents.

\section{Materials and Methods}

This study was carried out in Bhubaneswar, the state capital of Odisha. The Teaching Veterinary Clinical Complex (TVCC) of The College of Veterinary Science and Animal Husbandry was selected purposefully because itis the ultramodern clinical complex of the city with latest facilities for treatment of 
animals. The pet owners from all corners of the city come here for consultancy and treatment of their pets. 100 dog owners who visited to TVCC for treatment of their dogs during the month of January and February 2016 were selected on the basis of their willingness to participate in the study. They were first informed the purpose of the study, and data from them were collected personally by using structured questionnaire. Data obtained were analyzed using slandered statistical procedures. Demographic variables were presented using descriptive statistics and the mean knowledge scores were calculated. Respondents with knowledge scores equal or greater than the mean scores were considered to have good knowledge while those who had scores below the mean were categorized as having poor knowledge. Associations between demographic variables and the categorized scores were assessed using $\chi^{2}$ test.

\section{Results and Discussion}

\section{Demographic characteristics of the respondents}

Out of 100 respondents that participated in the study, 76 per cent were males and 24per cent were females.14per cent of the respondents were public servants while majority of them were i.e. 74 per cent were self-employed. So far, education level of the respondents are concerned majority of them i.e. 46 per cent of them were graduate and only 2 per cent of them are professionals.

\section{Association of dog owners with dogs}

The analysis of data presented in Table 2 reveals that majority of respondents i.e. 66 per cent have a single dog with them and 80per cent of them have more than five years of experience in of dog keeping and 54 per cent of the respondents are of the opinion that they keep dog for both luxury and guarding their house. Majority of the respondents i.e56 per cent had constructed kennel for their pet and only14 per cent allowed the dog to stay with the family members in the house.S tudy revealed that 60 per cent of the respondent did not allow their dogs to roam freely in the neighbourhood whereas 24 per cent of the respondents reported that they allow their dog to roam freely in the neighborhood.

\section{Knowledge of rabies}

Dog owners in this study showed an acceptable level of knowledge on mode of transmission of rabies, clinical signs of the disease and effects of licensing and registration of dog, but had poor knowledge of age of first vaccination of dogs. With a mean knowledge score of 5.01 in contrast to this finding higher knowledge and higher scores in practice indicators regarding rabies was reported from Sri Lanka (Gino et al., 2009). This difference probably is explained by the lack of health education programs about rabies in India. The respondents were categorized in to two categories, one category as good knowledge level having mean score above 5.01 and another one of poor knowledge level having less than or equal to mean score of 5.01. The number of respondents as per the category above presented in Table 3.

The responses of the respondents on various questions related to knowledge of rabies are compiled and presented in Table 4. The majority of the respondent $(86 \%)$ said that dogs are common source of rabies in India. 66 per cent of the respondents agreed that humans as well as dogs can be infected with rabies. However, $86 \%$ of the respondents are of the opinion that dog owners are more vulnerable to rabies than the non-dog owners. The study also revealed that majority of the respondent do not know at what age should dogs receive first dose of rabies vaccine and 
even $86 \%$ of respondents do not have the knowledge that vaccination of dogs against rabies should be repeated annually.

The results presented in Table 4 show statistical significant associations between age and knowledge of respondents. The respondents in the age group 20-30 are more knowledge and those in the age group of 19 and below are having least knowledge. Statistically significant association was observed between knowledge towards Rabies score and educational levels whereby higher levels of educations were associated with higher knowledge score. The statistically significant difference in knowledge score between males and females might be due to increased exposure of males in their daily life compared with females and better chance of acquiring correct information in prevention and control of Rabies. As far as occupation is concerned, it is positively associated with the knowledge score and this may again linked to their higher educational background and more exposure.

\section{Practices towards Control of Rabies}

Respondents were asked number of questions related to rabies and their responses were compiled, and presented in Table 5. The majority of the respondents i.e. 92 percent were of the opinion that a mad dog should not be allowed to roam freely, and around 94 per cent of them were in the view that dog registration and licensing helps in control of rabies. This indicates that the dog owners do have some knowledge towards effective control and prevention towards rabies.

Table.1 Demographic Characteristics of the Respondents

\begin{tabular}{|c|c|c|c|}
\hline \multicolumn{2}{|c|}{ Characteristics } & \multirow{2}{*}{$\begin{array}{c}\begin{array}{c}\text { Total number of } \\
\text { respondents }(\mathbf{N}=\mathbf{1 0 0})\end{array} \\
12\end{array}$} & \multirow{2}{*}{$\begin{array}{c}\text { Specific rates }(\%) \\
12\end{array}$} \\
\hline \multirow{4}{*}{ Age (years) } & $<19$ & & \\
\hline & $20-30$ & 72 & 72 \\
\hline & $31-40$ & 10 & 10 \\
\hline & $>40$ & 6 & 6 \\
\hline \multirow{5}{*}{ Educational status } & Under matriculate & 8 & 8 \\
\hline & Up to class 12 & 40 & 40 \\
\hline & Graduate & 46 & 46 \\
\hline & Post graduate & 4 & 4 \\
\hline & professional & 2 & 2 \\
\hline \multirow[t]{2}{*}{ Gender } & Male & 76 & 76 \\
\hline & female & 24 & 24 \\
\hline \multirow[b]{3}{*}{ Religion } & Hindu & 92 & 92 \\
\hline & Muslim & 8 & 8 \\
\hline & Christian & - & - \\
\hline \multirow[t]{3}{*}{ Occupation } & Unemployed & 12 & 12 \\
\hline & Public servant & 14 & 14 \\
\hline & Self employed & 74 & 74 \\
\hline
\end{tabular}


Table.2 Associations of dog owners with dogs

\begin{tabular}{|c|c|c|c|}
\hline \multicolumn{2}{|c|}{ Association item } & $\begin{array}{l}\text { Total number of } \\
\text { respondents }\end{array}$ & $\begin{array}{c}\text { Percentage } \\
(\%)\end{array}$ \\
\hline \multirow{4}{*}{$\begin{array}{c}\text { Period of dog keeping } \\
\text { (years) }\end{array}$} & $1-5$ & 62 & 62 \\
\hline & $6-10$ & 18 & 18 \\
\hline & $11-15$ & 14 & 14 \\
\hline & $>15$ & 6 & 6 \\
\hline \multirow{4}{*}{ Number of dogs owned } & 1 & 66 & 66 \\
\hline & 2 & 26 & 26 \\
\hline & 3 & 6 & 6 \\
\hline & $>3$ & 2 & 2 \\
\hline \multirow{4}{*}{$\begin{array}{c}\text { Reason for keeping } \\
\text { dogs }\end{array}$} & Companionship & 18 & 18 \\
\hline & For guarding & 10 & 10 \\
\hline & For luxury & 18 & 18 \\
\hline & $\begin{array}{c}\text { for both guarding and } \\
\text { luxury }\end{array}$ & 54 & 54 \\
\hline \multirow[t]{3}{*}{ Type of Dog housing } & Kennel (Dog house) & 56 & 56 \\
\hline & $\begin{array}{l}\text { Anywhere in the } \\
\text { premises }\end{array}$ & 30 & 30 \\
\hline & $\begin{array}{l}\text { With the family member } \\
\text { in the house }\end{array}$ & 14 & 14 \\
\hline \multirow[t]{3}{*}{$\begin{array}{l}\text { Control of dog } \\
\text { movement }\end{array}$} & $\begin{array}{l}\text { Never allowed leaving } \\
\text { the premises }\end{array}$ & 60 & 60 \\
\hline & $\begin{array}{l}\text { Allowed to roam freely } \\
\text { in the neighborhood }\end{array}$ & 24 & 24 \\
\hline & $\begin{array}{l}\text { Allowed movement with } \\
\text { owner only }\end{array}$ & 14 & 14 \\
\hline
\end{tabular}

Table.3 Number and percent of respondents according to Knowledge score levels about Rabies

\begin{tabular}{|c|c|c|}
\hline Knowledge score levels & Number & Percentage \\
\hline Poor $(<$ or = 5.01scores) & 67 & 67 \\
\hline Good (> 5.01scores) & 33 & 33 \\
\hline
\end{tabular}


Table.4 Relationships between knowledge scores about rabies and some key independent variables

\begin{tabular}{|c|c|c|c|c|c|}
\hline \multicolumn{2}{|c|}{ variables } & Poor & Good & $\chi^{2 s}$ & df \\
\hline \multirow[t]{4}{*}{ Age (years) } & $<19$ & 10 & 2 & \multirow[t]{4}{*}{$5.498^{*}$} & \multirow[t]{4}{*}{3} \\
\hline & $20-30$ & 26 & 10 & & \\
\hline & $31-49$ & 2 & 8 & & \\
\hline & $>40$ & 2 & 4 & & \\
\hline \multirow{5}{*}{$\begin{array}{c}\text { Educational } \\
\text { status }\end{array}$} & Under matriculate & 4 & 4 & \multirow[t]{5}{*}{$4.21 *$} & \multirow[t]{5}{*}{4} \\
\hline & up to lass 12 & 18 & 22 & & \\
\hline & Graduate & 14 & 28 & & \\
\hline & Post graduate & 2 & 4 & & \\
\hline & Professional & - & 4 & & \\
\hline \multirow[t]{2}{*}{ Gender } & Male & 26 & 50 & \multirow[t]{2}{*}{0.059} & \multirow[t]{2}{*}{1} \\
\hline & Female & 14 & 10 & & \\
\hline \multirow[t]{3}{*}{ Occupation } & Unemployed & 10 & 2 & \multirow[t]{3}{*}{$20.472^{* *}$} & \multirow[t]{3}{*}{2} \\
\hline & Public servant & 2 & 12 & & \\
\hline & Self employed & 36 & 38 & & \\
\hline
\end{tabular}

(*Significant at 0.05 level of probability)

(**Significant at 0.01 level of probability)

Table.5 Assessment of practice of respondents towards rabies

\begin{tabular}{|c|c|c|c|}
\hline Practice items & & Frequency & $\mathbf{( \% )}$ \\
\hline A mad dog should not be allowed to roam freely & Yes & 92 & 92 \\
\hline Dog registration and licensing helps in control \\
of rabies & No & 8 & 8 \\
\hline Have you been bitten by a dogs & Yes & 94 & 94 \\
\hline & No & 6 & 6 \\
\hline Do you have the knowledge about first aid treatment for dog & Yes & 28 & 28 \\
\hline bite? & No & 26 & 72 \\
\hline Dog handlers should wash their hand after feeding, grooming & No & 74 & 74 \\
\hline etc & Yes & 92 & 92 \\
\hline It is good to wash dog bite wounds with soap & No & 8 & 8 \\
\hline Dog handlers should take human anti rabies vaccine & Yes & 46 & 46 \\
\hline Wound treatment and Vaccination & No & 54 & 54 \\
\hline Vaccination and traditional medicine & Yes & 16 & 16 \\
\hline Herbal therapy & No & 84 & 84 \\
\hline Knowledge about governments animal birth control & & 68 & 68 \\
\hline programme & & 22 & 22 \\
\hline
\end{tabular}

Out of the 100 respondents, $28 \%$ of the respondent had the history of dog bite but majority of the respondent i.e. $74 \%$ do not have the knowledge about the first aid treatment required in case of their own dog bite. Though a good percentage i.e. $92 \%$ of them said that dog handlers should wash their hand after feeding, grooming etc, but $84 \%$ of them are not aware that dog handlers and owners should take human anti rabies vaccineas a preventive measure towards Rabies. Study revealed that $68 \%$ of the 
respondents go for wound treatment and vaccination in case of post dog bite still $10 \%$ of them go for traditional treatment like herbal therapy which is against WHO guideline of rabies treatment. Though animal birth control programme is the only programme to control rabies world-wide as recommended by $\mathrm{WHO}$, a large section of the sample population $74 \%$ of them were not aware about the government initiated animal birth control programme.

In conclusion the study reveals that dog owners of Bhubaneswar have knowledge about mode of transmission of rabies, clinical signs of the disease and importance of post bite vaccination to humans. But, they have poor knowledge on age of first vaccination, repeated annual vaccination and first aid measure for dog bite. The sate animal husbandry department, NGOs and civil societies may take up educational programme to aware the dog owners for adoption of recommended practices to control occurrence of rabies. The awareness campaign should focus on dog vaccination practices and knowledge of first aid treatments.

\section{References}

Agarwal, N., Reddaiah, V. P.2003. Knowledge, attitude and practice following dog bite: a community-based epidemiological study. Perspectives and Issues. 26:154-161.

Anita, K., Meena, D., and Malti, M., 2003.
Profile of dog bite cases attending M.C.D. Dispensary at Alipur, Delhi. Indian Journal of community medicine, 28(4):1012.

Jena B., Rao K., Reddy K., Raghavender K. 2013.Comparative efficacy of various therapeutic protocols in the treatment of pyometra in bitches. Veterinarni Medicina, 58: 271-276. https://doi.org/10.17221/6809VETMED

Lai, P., Rawat, A., Sagar, A., and Tiwari, K., 2005. Prevalence of Dog bite in Delhi: Knowledge and Practices of residents regarding prevention and control of rabies. Health and Population perspectives and Issues. 28(2):50-57.

Kaud HA. 2016. Canine Diseases (Medicine). Publisher: ISBN: 13: 978-1539420033, pp 1-2.

Sethi. G. P. S., V. K. Gandotra, M. Honparkhe, A. K. Singh, A. K. Arora and Ghuman. S. P. S. 2020. Efficacy of Antiprogesterone and PGF2 $\alpha$ Therapy for Treating Canine Pyometra. Int.J.Curr.Microbiol.App.Sci. 9(2):2117 $-2123$.

doi: https://doi.org/10.20546/ijcmas.202 0.902 .240

WHO, 2007. WHO recommendations on rabies post-exposure treatment and the correct technique of intradermal immunization against rabies: Geneva, Switzerland.

\section{How to cite this article:}

Das, B. C., S. R. Khatua, V. S. Shivani, S. Samanta and Priyadarshini, N. 2021. Study on Knowledge level of Dog Owners towards Rabies Prevention and Control. Int.J.Curr.Microbiol.App.Sci. 10(01): 3293-3299. doi: https://doi.org/10.20546/ijcmas.2021.1001.384 